\title{
Advances in Parenteral Nutrition Support of Children with Neoplastic Diseases *
}

\author{
K. A. Rickard, J. L. Grosfeld, T. D. Coates, R. M. Weetman, A. J. Provisor \\ and R. L. Baehner
}

\section{A. Introduction}

In the last decade, advances were made in understanding the significance of protein energy malnutrition (PEM), in recognizing PEM in specific subpopulations of children with malignancies, in staging and assessment of nutritional status, and in understanding the efficacy and limitations of various options for nutrition support. This report describes our experience in providing nutrition support for over a 100 children with newly diagnosed malignancies who have been monitored carefully on study protocols and treated at a single pediatric cancer facility. This work was possible because of the close collaboration between the Departments of Pediatric Hematology Oncology, Pediatric Surgery, Radiation Oncology, and Pediatric Nutrition and Dietetics at James Whitcomb Riley Hospital for Children.

\section{B. Significance of PEM}

PEM is associated with impaired immunocompetence, increased susceptibility to infections, major organ dysfunctions, and, when severe, increased morbidity and mortality. The organ systems most readily affected by PEM, i.e., the hematopoietic,

* Departments of Pediatric Nutrition and Dietetics, Pediatric Hematology Oncology and Pediatric Surgery. James Whitcomb Riley Hospital for Children, Indiana University School of Medicine, 702 Barnhill Drive, Indianapolis, Indiana 46223, USA gastrointestinal, and immunologic systems, are also those which are the most sensitive to oncologic treatment. Improvement in these systems may be one of the goals for either reversing or preventing PEM.

In an initial study [9] of children with newly diagnosed advanced solid tumors and relapsed leukemia-lymphoma, anergy (as defined by the inability to respond to any one of four recall skin test antigens) was documented in 17 of 18 patients considered malnourished. Anergy was reversed with 28 days of central parenteral nutrition support in approximately two-thirds of the patients $(7 / 11$ retested), despite continuing oncologic treatment. Van Eys et al. [17] documented significantly higher rates of infectious complications in malnourished compared with well-nourished children with metastatic disease involving bone who received parenteral nutrition support. Current data suggest that bone marrow suppression may be attenuated by parenteral nutrition support, at least in patients with stages III and IV neuroblastoma [12, 15], patients with acute nonlymphocytic leukemia (ANLL [7]), and patients with metastatic disease involving bone [17]. Nutritional status at the time of diagnosis of neoplastic disease has been clearly associated with outcome in adults [2] as well as children $[3,12]$.

\section{Childhood Neoplasms with High Risk for PEM}

PEM is a common occurrence in certain high risk populations of children with neo- 
plastic diseases. The incidence of PEM at diagnosis of childhood neoplasms and during treatment of childhood cancer varies from $6 \%$ (children with newly diagnosed leukemia) to as high as 50\% (children with newly diagnosed stage IV neuroblastoma), depending upon tumor type, stage of disease, and criteria for PEM [11]. We sequentially monitored the nutritional status (energy intakes, weights, weight for height proportionality, skinfold measurements, albumin, and transferrin) of more than 100 children with newly diagnosed neoplastic diseases during initial phases of therapy. These data formed the basis for determination of the factors that place a patient at a higher risk for the development of PEM (Table 1). The tumor types usually associated with high and low nutritional risk are listed in Table 2.

\section{Staging and Assessment of Nutritional Status}

In the past, states of malnutrition may have been overlooked because of lack of tangible criteria for establishing the nutritional

Table 1. Common risk factors for the development of PEM

\section{Advanced disease}

Lack of tumor response

Abdominal and pelvic irradiation

Intense frequent courses of chemotherapy ( $\leqq 3$ weeks) in the absence of corticosteroids or appetite stimulants

Major operative procedures of the abdomen

Psychologic factors, removal from familiar surroundings, separation from parents and siblings

Absence of supportive health care team status of these patients, or, possibly owing to an insensitivity to the significance of PEM. We developed a system for nutrition staging patients not only at diagnosis, but also during ongoing oncologic treatment because changes in nutritional status are dynamic.

\section{Identification of PEM (Staging) at Diagnosis}

Criteria for staging patients as malnourished at diagnosis include: $>5 \%$ weight loss, weight for height $<5$ th percentile, or serum albumin $<3.2 \mathrm{~g} / \mathrm{dl}$. A patient who does not meet any of these criteria is staged as well-nourished. The significance of nutrition staging at diagnosis has been emphasized in a recent study [12] of 18 of our children with newly diagnosed stage IV neuroblastoma. In an equal number of malnourished and well-nourished patients at diagnosis, significantly more malnourished patients had relapsed or died by 180 days after treatment was initiated $(P<$ $0.05)$. The differences in survival between the two groups of patients approached significance $(P=0.08)$ at 1 year into treatment. The median survival of the malnourished group was 5 months compared with 12 months for the well-nourished group. It remains to be determined whether the patients considered to be malnourished at diagnosis have a more aggressive or advanced form of neuroblastoma, or, whether the nutritional status influenced the outcome.

\section{Ongoing Nutritional Assessment}

Dramatic changes in nutritional status have occurred over as short a period as 1 week

Table 2. Types of neoplastic disease associated with high and low nutritional risk

High nutritional risk

Stage III and IV Wilms' tumor

Advanced neuroblastoma

Acute nonlymphocytic leukemia

Pelvic rhabdomyosarcoma

Brain tumor

Some non-Hodgkin's lymphomas

\section{Low nutritional risk}

Acute lymphocytic leukemia

Nonmetastatic diseases

Advanced diseases during maintenance treatment and when in remission 
because of the almost immediate adverse impact of oncologic treatment upon the gastrointestinal system and upon nutrient intake. The current criteria used for staging patients at diagnosis may not be sensitive enough to detect ongoing nutritional depletion.

Some pitfalls may be associated with the monitoring of weight changes as the only index of nutritional status. Children who are $<5$ th percentile weight for height have relatively small losses in weight compared with well-nourished children with equally low energy intakes. Malnourished children have fluid changes which mask some of the tissue wasting. Edema and dehydration may alter weight so that accurate interpretation is difficult. Furthermore, monitoring only absolute weight changes may provide a false sense of security. Weights need to be plotted sequentially on growth grids and expressed as a percentage of weight loss. For example, a $2 \mathrm{~kg}$ weight loss for a $60 \mathrm{~kg}$ teenager (3\% weight loss) may not seem impressive, however, the same $2 \mathrm{~kg}$ loss in a $20 \mathrm{~kg}$ toddler represents a $10 \%$ weight loss.

Changes in weight, weight for height, and subscapular skinfold thickness are particularly useful indicators of real or impending nutrition depletion. Low energy intakes and decreases in skinfold measurements were the first indicators of nutrition depletion and occurred despite weight maintenance or a slight weight gain in several children who had no evidence of edema. Fomon and associates [5] reported a similar phenomenon in normal infants fed skim milk formula (67\% of energy requirement). This group of babies experienced approximately $25 \%$ decreases in triceps and subscapular skinfold measurements even though they gained weight, albeit at a slower rate than normal.

Skinfold calipers are valuable in detecting more subtle, subclinical changes in nutritional status during early phases of treatment. Subscapular skinfold decreases $>0.3 \mathrm{~mm}$ correlated with low energy intakes (more than 2 standard deviations below the mean of Beal's data [1] for healthy children) in patients who initially had skinfold measurements in the normal range. Changes $>0.3 \mathrm{~mm}$ are twice the coefficient of variation which was determined from 265 data sets for each subscapular skinfold measurement.

For ongoing nutritional assessment, albumin concentrations in relation to energy intake are monitored. Albumin is a useful indicator of mild to moderate PEM in some patients, i.e., decreases are seen which correspond to very low protein or energy intakes and may be observed before significant weight loss. However, albumin concentrations may be preserved at marginal or low ranges of normal $(2.9-3.2 \mathrm{~g}$ / dl) in some children with obvious tissue wasting. Transferrin, prealbumin, and retinol binding proteins are serum proteins which may indicate subclinical PEM. They have shorter half-lives and different synthetic rates than albumin. In a current study [14] of these biochemical indicators, preliminary data strongly support the use of these serum proteins as early indicators of successful repletion.

\section{E. Options for Nutritional Support}

\section{Enteral Nutrition}

Several modes of nutrition support are available for the pediatric patient. For most children with cancer, provision of nutrients by the enteral route with oral feeding is the preferred method because treatment may last several years. An individualized feeding program which uses favorite, nutritious foods of the child during treatment-free periods has numerous practical and psychologic advantages over parenteral nutrition. These include a lower risk of infection and other catheter-related complications, more normal play activities and life-style, and a positive way for parent and child to be involved in their own care. In addition, enteral feeding is more economic. In our experience, however, this type of enteral feeding program has not been effective in either preventing or reversing PEM in most of the patients at high nutritional risk during initial intense treatment. In a study [9] of 21 children with advanced cancer who were enterally nourished, energy intake was very low, averaging $48 \% \pm 24 \%$ of the Recommended Dietary Allowances (RDA) for kilocalories, 
and weight loss averaged $16 \%$ in less than 1 month of treatment. Similarly, in a recent study of 32 children with stages III and IV neuroblastoma [15] significant loss of fat reserves and weight occurred during the initial 28 days of treatment when enteral nutrition alone was provided. The children who became malnourished were unable to make nutritional gains thereafter, despite numerous delays in treatment.

We feel that the use of nasogastric tubes to provide nutrition is contraindicated in the older infant, toddler, and preschool age groups of children because of psychologic trauma associated with the insertion and maintenance of tubes. Nausea and vomiting in addition to decreased intestinal motility and absorption from oncologic therapy make this modality less favorable and less effective. Gastrostomy feedings also seem to be of limited value for similar reasons. In a few older schoolage and teenage children, continuous nasogastric nighttime feedings have been beneficial.

\section{Parenteral Nutrition}

\section{Nutritional and Immunologic Benefits}

Parenteral nutrition is both safe $[18,13]$ and efficacious in children with neoplastic diseases. In a group of 28 patients who had stage III or IV solid tumors or second relapse leukemia-lymphoma, the effectiveness of central parenteral nutrition (CPN) in reversing PEM and restoring immunity was documented [9]. Of the 28 patients who were malnourished, 20 received CPN for a mean of 24 days (average caloric intake of $90 \%$ of the RDA during weight gain). Initially, patients were randomized to either 10 or 28 days of CPN. The 10 -day randomization was abandoned after the initial three patients rapidly returned to their initial malnourished state because of continuing oncologic treatment. Review of data from 20 patients who received longer intervals ( $\geqq 28$ days) of parenteral nutrition indicated that shorter intervals (9-14 days) did not restore an appropriate weight for height (though weight gains were significant) nor fat reserves, and, did not return serum albumin concentrations to $\geqq 3.2 \mathrm{~g} /$ dl. Despite the failure of shorter intervals of parenteral nutrition to reverse PEM, an improvement in transferrin concentration occurred, suggesting that transferrin was more responsive than albumin. Another short-term benefit was a significant improvement in the child's general state of well-being. A period of 28 days CPN restored weight for height percentiles, subscapular skinfold percentiles, albumin, and transferrin concentrations to normal values. Curtailment of parenteral nutrition support before reversal of PEM and completion of intensive oncologic support reduced the benefits of previous nutrition support. Therefore, we recommend continuing the parenteral nutrition support for several days beyond cessation of chemotherapy or irradiation treatment which induce anorexia, nausea, and vomiting. Nutritional benefits from effective parenteral nutrition support are maintained after completion of the intense treatment, unless complicating factors in the patient's clinical course such as relapse, sepsis, or major abdominal procedures occur $[10,15]$.

In a recent study [13] comparing the effectiveness of parenteral nutrition provided by either central or peripheral veins, the central line allowed provision of greater concentrations of glucose and obviated problems with subcutaneous peripheral infiltrations. In 19 children with advanced neuroblastoma or Wilms' tumor, both routes of administration were effective in reversing PEM when adequate energy and protein were provided over a 21 - to 28-day period. Significant increases in anthropometric measurements and albumin were similar for the two groups. Both groups had a similar incidence of anemia, fever episodes (with and without documented sepsis), and mildly elevated SGOT concentrations. The peripheral parenteral nutrition (PPN) group, however, had a high incidence of line changes associated with peripheral infiltrations and related psychologic trauma. In this study, the effectiveness of PPN was dependent upon an oral intake which provided an average of $30 \%$ additional energy to meet the RDA. Based upon these results, a central line is used for our standard parenteral nutrition support program and a peripheral line for periods when the central line is interrupted. 


\section{Treatment Tolerance Benefits}

Treatment tolerance benefits from parenteral nutrition compared with oral nutrition have been documented in several recent prospective randomized studies of children with specific tumors. In an initial report of a randomized study [12] of $17 \mathrm{pa}-$ tients with stage IV neuroblastoma, those who had a favorable nutrition course during the first 21 days of therapy had significantly fewer treatment delays (secondary to absolute granulocyte counts $\geqq 1000 / \mu \mathrm{l}$ or platelets $\geqq 75000 / \mu \mathrm{l}$ ) and fewer drug dose reductions throughout the first 10 weeks of treatment. Treatment consisted of 5-day cycles of DTIC, vincristine, and cyclophosphamide given at 3-week intervals. The treatment tolerance benefits from effective reversal or prevention of PEM were further documented in 32 patients with stages III and IV neuroblastoma [15].

Three other prospective randomized studies of children with cancer have also documented treatment benefits from CPN compared with oral nutrition in improving tolerance to chemotherapy [17], in improving adherence to chemotherapy schedules [6], or in accelerating recovery of normal marrow function [7]. In contrast to these findings, Shamberger et al. [16] failed to document benefit from CPN compared with oral nutrition in improving recovery from bone marrow suppression in a series of 27 young patients who received extremely aggressive treatment for poor prognosis sarcomas. In a multi-institutional study [4] of 25 patients who received abdominal irradiation, the CPN and oral nutrition groups of patients did not differ in ability to adhere to the radiotherapy schedule. Thus, the value of CPN in improving treatment tolerance probably relates to certain types and stages of tumors as well as specific treatment.

\section{Complications and Limitations}

Complications can be minimized or safely controlled with careful patient management and strict adherence to a parenteral nutrition protocol. In a multi-institutional study of complications of adults with cancer randomized to either CPN (125 patients) or control groups (126 patients),
Mullen [8] reported that CPN adds little serious morbidity and mortality. An increased incidence of fever $(P<0.003)$, anemia $(P<0.09)$, and pulmonary dysfunction $(P<0.12)$ was documented in the CPN group, however, incidence of documented infections (25\%) at distant sites was similar for both groups.

The possibility that CPN stimulates tumor growth in excess of host repletion needs to be considered, although clinically this has not been observed when aggressive oncologic treatment is given simultaneously. In fact, it is conceivable that CPN may beneficially stimulate cell replications and increase effectiveness of cellcycle-specific drugs. Certainly, tumor response may be improved when effective oncologic treatment is completed on schedule.

Acknowledgments. This work was supported in part by grants RO1-CA 28531 and RO1-CA 28005 from the National Cancer Institute, Bethesda, Maryland 20205.

\section{References}

1. Beal VA (1970) Nutritional intake. In: McCammon RW (ed) Human growth and development. Thomas, Springfield, Ill, pp 63-100

2. DeWys WD, Begg C, Lavin PT, Band PR, Bennett JM, Bertino JR, Cohen MH, Douglass HO, Engstrom PF, Ezdinli EZ, Horton J, Johnson GJ, Moertel CG, Oken MM, Perlia C, Rosenbaum C, Silverstein MN, Skeel RT, Sponzo RW, Tormey DC (1980) Prognostic effect of weight loss prior to chemotherapy in cancer patients. Am $J$ Med 60:491-497

3. Donaldson SS, Wesley MN, DeWys WD, Suskind RM, Jaffee N, Van Eys J (1981) A study of the nutritional status of pediatric cancer patients. Am J Dis Child 135: 1107-1112

4. Donaldson SS, Wesley MN, Ghavimi F, Shils ME, Suskind RM, DeWys WD (1982) A prospective randomized clinical trial of total parenteral nutrition in children with cancer. Med Pediatr Oncol 10: 129-139

5. Fomon SJ, Filer LJ, Ziegler EE, Bergmann KE, Bergmann RL (1977) Skim milk in infant feeding. Acta Pediatr Scand 66: 17-30

6. Ghavimi R, Shils ME, Scott BF, Brown M, Tamaroff $M$ (1982) Comparison of morbidity in children requiring abdominal radiation 
and chemotherapy with and without total parenteral nutrition. J Pediatr 101:4: 530-537

7. Hays DM, Merritt RJ, Ashley J, White L, Siegel SE (1983) Effect of total parenteral nutrition on marrow recovery during induction therapy for acute nonlymphocytic leukemia in childhood. Med Pediatr Oncol 11:134-140

8. Mullen J (1981) Complications of total parenteral nutrition in the cancer patient. Cancer Treat Rep 65 [Suppl 5]: 107-113

9. Rickard KA, Grosfeld JL, Kirksey A, Ballantine TVN, Baehner RL (1979) Reversal of protein-energy malnutrition in children with advanced neoplastic disease. Ann Surg 190: 771-781

10. Rickard KA, Kirksey A, Baehner RL, Provisor AJ, Weetman RM, Ballantine TVN, Grosfeld JL (1980) Effectiveness of enteral and parenteral nutrition in the nutritional management of children with Wilm's tumor. Am J Clin Nutr 33:2622-2629

11. Rickard KA, Baehner RL, Coates TD, Weetman RM, Provisor AJ, Grosfeld JL (1982) Supportive nutritional intervention. Cancer Res 42 [Suppl]: 766-773

12. Rickard KA, Detamore DM, Coates TD, Grosfeld JL, Weetman RM, White NM, Provisor AJ, Boxer LA, Loghmani ES, Oei TO, Yu P, Baehner RL (1983a) Effect of nutrition staging on treatment delays and outcome in stage IV neuroblastoma. Cancer 52: 587-598

13. Rickard KA, Foland BB, Detamore CM, Coates TD, Grosfeld JL, White NM, Weetman RM, Provisor AJ, Loghmani ES, Oei TO, Yu P, Baehner RL (1983 b) Effectiveness of central parenteral nutrition vs peripheral parenteral nutrition plus enteral nutrition in reversing PEM in children with advanced neuroblastoma and Wilms' tumor: a prospective randomized study. Am J Clin Nutr 38:445-456

14. Rickard KA, Foland BB, Grosfeld JL, Loghmani ES, Yu P, Detamore CM, Coates TD, Weetman RM, Provisor AJ, Oei TO, Baehner RL (1984 a) Prealbumin and retional binding protein: Early biochemical indicators of nutritional repletion in children with neuroblastoma or Wilms' tumor. Fed Proc 43:468 (Abstract 1070)

15. Rickard KA, Loghmani ES, Grosfeld JL, Detamore CM, White NM, Foland BB, Coates TD, Yu P, Weetman RM, Provisor AJ, Oei TO, Baehner RL (1984 b) Effectiveness of enteral and parenteral nutrition in preventing and/or reversing PEM in children with advanced neuroblastoma. Am Soc Clin Oncol Proc 3: 109 (Abstract C-423)

16. Shamberger RC, Pizzo PA, Goodgame JT, Lowry SF, Maher MM, Wesley RA, Brennan MF (1983) The effect of total parenteral nutrition on chemotherapy-induced myelosuppression. Am J Med 74:40-48

17. Van Eys J, Copeland EM, Cangir A, Taylor G, Teitell-Cohen B, Carter P, Ortiz C (1980) A clinical trial of hyperalimentation in children with metastatic malignancies. Med Pediatr Oncol 8:63-73

18. Van Eys J, Wesley MN, Cangir A, Copeland EM, Donaldson SS, Ghavimi F, Shils $M$, Suskind R, Jaffe N, Filler R (1982) Safety of intravenous hyperalimentation in children with malignancies: A cooperative group trial. JPEN 6:291-294 